Journal of Ancient Philosophy Vol. IV 2010 Issue 2

\title{
A short notice on Robert Heinaman's account of Aristotle’s definition of kívnoıs in Physica III
}

Javier Echeñique Sosa (PhD - St Andrews)

In Physica III. 1-2 we can find at least two explicit definitions of change

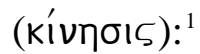

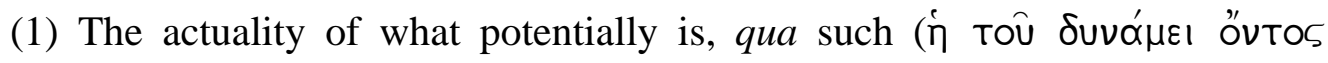

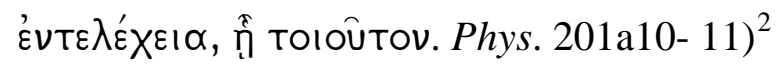

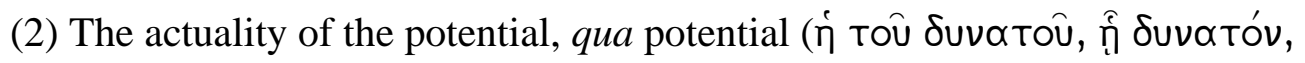

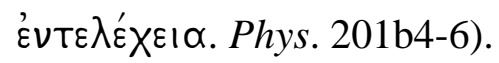

This definition of change has been the focus of intense debate amongst modern scholars. ${ }^{3}$ In an influential article, Robert Heinaman has advanced an interpretation of this definition, according to which the potentiality involved in the definition of change is a potentiality to change (to F) - as opposed to a potentiality for being the end-state of a change (i.e. F). Heinaman points to different versions of the definition in which the potentiality involved in change is explicitly specified as a potentiality to change (to F). I will consider what Heinaman takes to be the unambiguous formulations: ${ }^{4}$

\footnotetext{
${ }^{1}$ I won't consider the one at the end of Phys. III. 3 (202b26-7), which I take to be a reformulation of the original definition in terms of agency and patiency.

${ }^{2}$ I use W. D. Ross edition, Ross, W. D (1936): Aristotle’s Physics. Oxford: Clarendon Press. I follow here most commentators (including Heinaman himself) in rejecting Ross' translation of

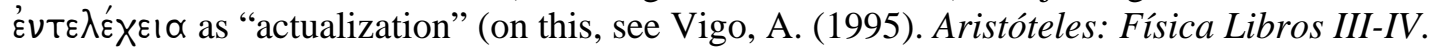
Buenos Aires, Biblos. Pp. 109-110).

${ }^{3}$ Some examples are: Heinaman, R. (1994). 'Is Aristotle's Definition of Change Circular?', Apeiron 27: 25-37; Kosman, L. A. (1969). 'Aristotle's Definition of Motion', Phronesis 14: 40-62; Kostman, J. (1987). 'Aristotle's Definition of Change', History of Philosophy Quarterly 4: 3-16; Waterlow, S. (1982). Nature, Change and Agency in Aristotle's Physics, Oxford: Oxford University Press.
}

${ }^{4}$ A complete list of the different formulations of the definition in the Physics is provided by Heinaman, R. (1994). The ones I quote, (2), (3) and (7) (corresponding to my (3), (4) and (5) 
Journal of Ancient Philosophy Vol. IV 2010 Issue 2

(3) The actuality of the alterable (той $\alpha \lambda \lambda$ oเ 201a11-12).

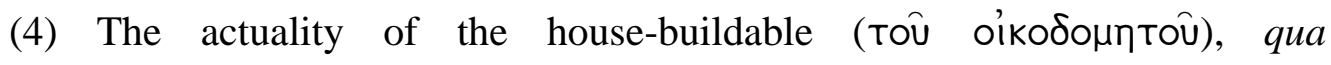
house-buildable (Phys. 201b9-10).

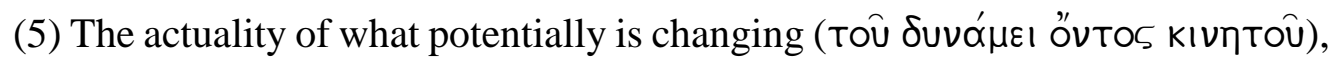
qua potentially changing (inferred from Phys. 202a3-4).

These formulations are taken by Heinaman to complete what in (1) and (2) is omitted, rather than to be in conflict with them. This is particularly obvious in (5), for Kıvワтoú and the qua clause here specified can easily be taken to complete (1). What I want to argue is that, even though Heinaman's interpretation of the definition of change and the evidence he points at in his article do show that there is an ambiguity in the definition of change as to which kind of potentiality Aristotle is referring to, they do not decisively establish that the potentiality involved in the definition of change is not a potentiality for being the end-state of a change.

First of all, there is no such definition as (5) in Aristotle's text. Heinaman argues that we can safely infer (5) from the following passage:

As we said, everything that produces change is also changed, if it is potentially

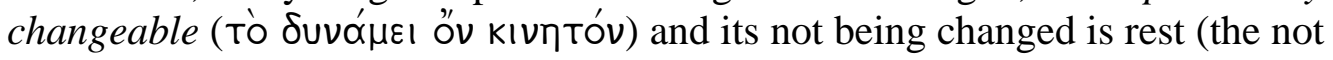
being changed of that which admits of change is rest). For to operate on this, qua such, is just what it is to produce change, and this it does by contact, so that it will at the same time also be acted upon (Phys. 202a3-7). ${ }^{5}$

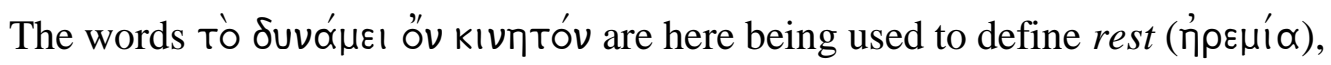

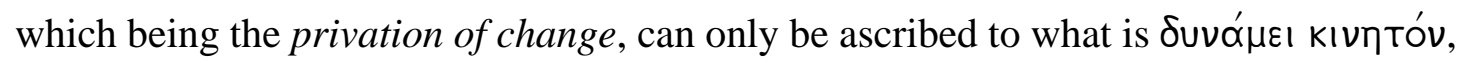
that is, to what is potentially changeable. That is, being a privation, rest must presuppose the concept of change and must be defined in terms of it. But there is no suggestion here that this must also be the case with the definition of change itself (i.e.

respectively), are taken from this article.

${ }^{5}$ Aristotle continues: "because of this, change is the actuality of the changeable (Kıvๆróv) qua changeable ...." (202a7). This explicit passage would support Heinaman's view if it were not for

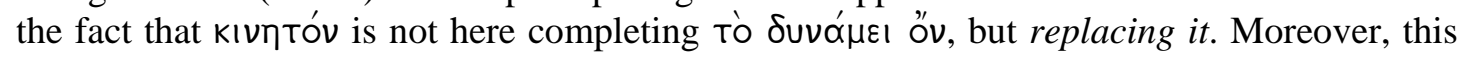
passage occurs in a context in which Aristotle is working out his reformulation of the definition of change in terms of agency and patiency, and Heinaman has not shown that this reformulation is equivalent to the original definition. It is also worth pointing out that Edward Hussey excludes this passage (202a7-9) from his translation (See Hussey, E. (1983). Physics: Books III and IV. Clarendon Aristotle Series. Oxford: Oxford University Press). 
Journal of Ancient Philosophy Vol. IV 2010 Issue 2

that change itself must be circularly defined in terms of what has the potentiality to

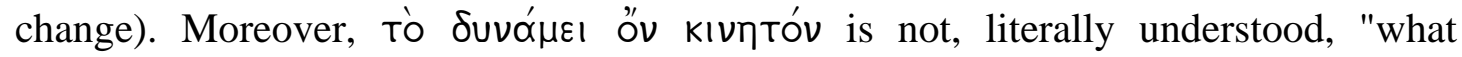
potentially is changing" (as Heinaman translates it), but "what potentially is changeable".

But what about (3) and (4)? First, it is worth noting that (3) and (4) are not definitions of change as such, but of alteration and house-building respectively. The only general definitions of change that we get from Aristotle (apart from the one at the end of Chapter 3 in terms of agency and patiency) are (1) and (2). I think that, (5) being eliminated from the picture, what definitions (3) and (4) show (jointly with the three remaining definitions of locomotion, increase and decrease, and coming to be and ceasing to be at Phys. 201a10ff) is, at most, a conflict with the general definitions of change, (1) and (2).

That this is the case is strongly suggested, first, by the general definition of

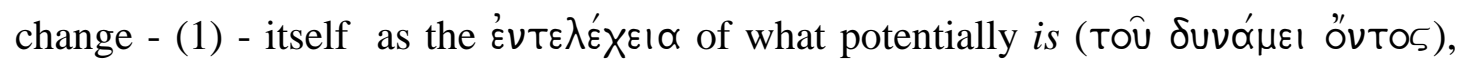
where, in the absence of independent evidence like (5), "what potentially is" is not to be taken as meaning "what potentially is changing". There is no suggestion in Aristotle's

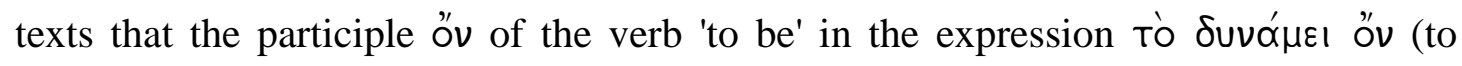
formulate (5) in the nominative) is to be taken exclusively as elliptical or as a copula;

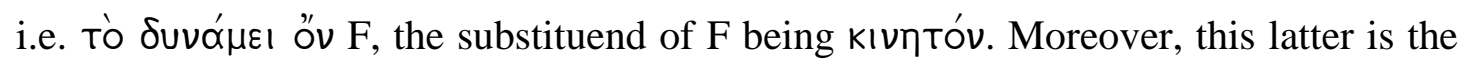
only substituend which Heinaman can appeal to, and we have already noticed that it will not do the job Heinaman requires, for it means "changeable", thus rendering the meaning of the expression unintelligible (i.e. what is potentially changeable).

Secondly, the first definition of change - (1) above - is introduced by the following words:

Having distinguished what is actually and what is potentially according to each kind <of being>, change is the actuality of what is potentially, qua such, for instance, the actuality of what is alterable, qua alterable, is alteration, ... (Phys. 201a9-12) ${ }^{6}$

In the first two lines, Aristotle is pointing out to his previous argument (Phys. 200b26-201a9), according to which there is no change over and above the categories, and more specifically, that change always takes place between opposite

\footnotetext{
${ }^{6}$ Translations are mine.
} 
Journal of Ancient Philosophy Vol. IV 2010 Issue 2

determinations $^{7}$ (e.g. white and black, complete and incomplete, upwards and downwards, etc.) in certain categories. This is just a specification of Aristotle's previous discussion in Phys. I. 7, according to which change is always from form to privation, and from privation to form, where privation and form, at least in the less problematic case of non-substantial becoming, are to be understood as predicates. What Aristotle

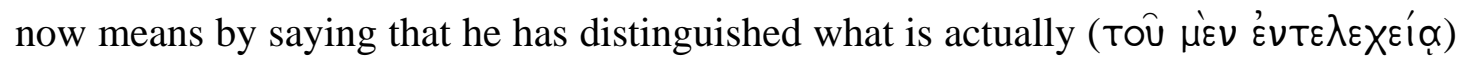
and what is potentially (тố $\delta^{\prime} \varepsilon \delta \cup v \alpha{ }^{\prime} \mu \varepsilon ı$ ) according to each category, is that change takes place between something $\mathrm{X}$ being potentially $\mathrm{F}$ at $t$ (being actually non-F) and the same thing $\mathrm{X}$ being actually $\mathrm{F}$ at $t^{\prime}$, where $\mathrm{F}$ and non- $\mathrm{F}$ are opposite predicates within the same category. There is no suggestion in the line of argument developed in the whole preface to the definition of change for the claim that, as subscribed to the

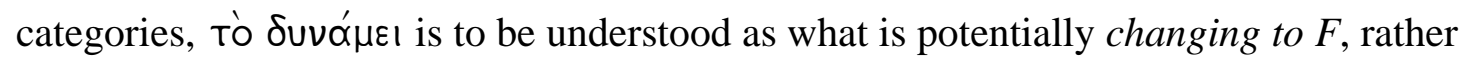
than what potentially is $\mathrm{F}$.

And finally, the conflict is stressed by some evidence which Heinaman does not consider as telling against his own interpretation. I mean, for instance, Aristotle's claim

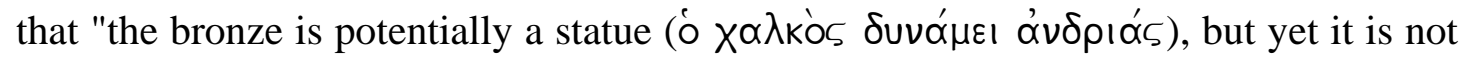
the actuality of bronze qua bronze that is change" (Phys. 201a30), where it is natural to complete the sentence with "but the actuality of the bronze qua potentially a statue". Heinaman thinks these lines do not constitute evidence against his interpretation because he reads the immediately following lines (201a31-32) as follows: "For the

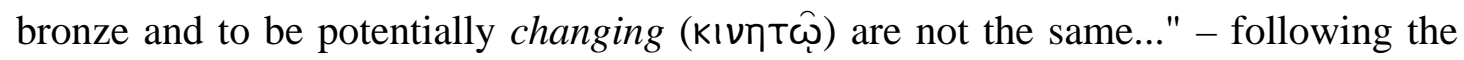

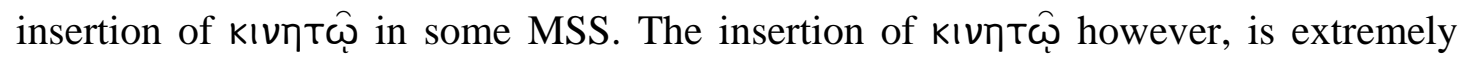
dubious: it is omitted in the parallel text of Metaphysica 1065b26, which is probably why David Ross omits it in his Oxford edition of the Physica.

I conclude, therefore, that Heinaman's interpretation of the definition of change and the evidence he points at in his article can only show that there is an ambiguity in the definition of change as to which kind of potentiality Aristotle is referring to (an ambiguity that is, perhaps, deeply rooted in Aristotle's metaphysics, and that must be adequately explained). They do not decisively establish, however, that the potentiality

\footnotetext{
${ }^{7}$ I use the word 'determination' instead of predicate, because substantial form is not a predicate.
} 
Journal of Ancient Philosophy Vol. IV 2010 Issue 2

involved in the definition of change is not a potentiality for being the end-state of a change.

\section{Bibliography}

Heinaman, R. (1994). 'Is Aristotle's Definition of Change Circular?' Apeiron 27: 25-37. Hussey, E. (1983). Physics: Books III and IV. Clarendon Aristotle Series. Oxford: Oxford University Press.

Kosman, L. A. (1969). 'Aristotle's Definition of Motion'. Phronesis 14: 40-62.

Kostman, J. (1987). 'Aristotle's Definition of Change.' History of Philosophy Quarterly 4: 3-16.

Ross, W. D. (1936). Aristotle’s Physics. Oxford: Clarendon Press.

Vigo, A. (1995). Aristóteles: Física Libros III-IV. Buenos Aires, Biblos.

Waterlow, S. (1982). Nature, Change and Agency in Aristotle's Physics, Oxford: Oxford University Press. 